\title{
Processamento mínimo de tangor 'Murcott': tipos de corte, sanificação e eliminação do excesso de líquidos
}

\author{
Minimal processing of 'Murcott' tangor: types of cut, sanification and \\ elimination of excess fluids
}

\section{Rodrigo Frigério Chiarini ${ }^{1}$, Angelo Pedro Jacomino ${ }^{1 *}$, Maria Cecilia de Arruda-Palharini ${ }^{2}$, Aline Priscilla Gomes da Silva ${ }^{1}$, Carolina Amanda Wippich Andrade ${ }^{1}$}

\author{
1 Universidade de São Paulo (USP), Escola Superior de Agricultura "Luiz de Queiroz" (ESALQ), Departamento de Produção Vegetal, Piracicaba/SP - Brasil
}

2 Polo Regional Centro Oeste (APTA/SAA), Bauru/SP - Brasil

\section{${ }^{*}$ Corresponding Author}

Angelo Pedro Jacomino, Universidade de São Paulo (USP), Escola Superior de Agricultura "Luiz de Queiroz" (ESALQ), Departamento de Produção Vegetal, Av. Pádua Dias, 11, Caixa Postal: 9, CEP: 13418-900, Piracicaba/SP - Brasil, e-mail: jacomino@usp.br

Cite as: Minimal processing of 'Murcott' tangor: types of cut, sanification and elimination of excess fluids. Braz. J. Food Technol., v. 20, e2016041, 2017.

Received: Apr. 06, 2016; Accepted: Feb. 06, 2017

\section{Resumo}

O tangor 'Murcott' é uma das variedades de tangerina mais produzidas no Estado de São Paulo. Apresenta excelente qualidade sensorial e sabor intenso e mais doce do que a tangerina 'Ponkan', sendo, dessa forma, um produto com potencial para o mercado de frutos minimamente processados. Diante disso, o objetivo deste trabalho foi determinar os efeitos dos tipos de corte e dos métodos de sanificação e de eliminação do excesso de líquidos na qualidade de tangor 'Murcott' minimamente processado. Num primeiro experimento, os frutos foram cortados em metades, tiras e cubos. No segundo experimento, foram estudados os efeitos dos métodos de sanificação com cloro e de eliminação do excesso de líquidos. Os cortes em metades e em tiras apresentaram maiores teores de ácido ascórbico no final do armazenamento. O teor de sólidos solúveis não diferiu entre os cortes. O corte em tiras apresentou teores baixos de acidez titulável e elevada relação sólidos solúveis/acidez titulável. A eliminação do excesso de líquidos não afetou a aparência do produto minimamente processado e a sanificação com cloro não afetou o sabor. Todos os tratamentos apresentaram baixos níveis de contaminação microbiana nas condições do presente estudo. O melhor tipo de corte foi o de tiras. A sanificação após o corte, bem como a eliminação do excesso de líquidos, mostraram-se dispensáveis no processamento mínimo de tangor 'Murcott' em tiras, nas condições do presente estudo.

Palavras-chave: Citrus reticulata Blanco x Citrus sinensis (L.) Osbeck; Pós-colheita; Centrifugação; Qualidade microbiológica.

\section{Abstract}

'Murcott' is one of the tangerine varieties most produced in São Paulo, Brazil. It presents excellent sensory quality, intense flavour and is sweeter than the 'Ponkan' tangerine, and is therefore a product with potential for the minimally processed fruits market. The aim of this study was to determine the effects of types of cutting, sanitation methods and the elimination of excess fluids on the quality of minimally processed 'Murcott' tangor. In the first experiment, the fruits were cut into halves, strips and cubes. In the second experiment the effects of chlorine sanitization and the elimination of excess fluids were examined. The halves and strips showed higher ascorbic acid contents at the end of the storage period than did the cubes, but the soluble solids contents did not differ significantly between the cuts. The strips showed low titratable acidity levels and high soluble solids/titratable acidity ratios. The elimination of excess fluid did not affect the appearance of the minimally processed products, and sanitization with chlorine did not affect the taste. All the treatments showed low levels of microbial contamination under the conditions of the present study. The strips were the best type of cut. Under the conditions of this study, sanitation after cutting and the elimination of excess fluid were proven to be expendable in the minimum processing of 'Murcott' as strips.

Keywords: Citrus reticulata Blanco x Citrus sinensis (L.) Osbeck; Postharvest; Centrifugation; Microbiological quality. 


\section{Introdução}

O Brasil destaca-se como um dos maiores produtores mundiais de tangerinas, apenas superado pela China e pela Espanha. A produção brasileira de tangerinas, em 2014, foi em torno de 938 mil toneladas, colhidas em uma área de aproximadamente 49.857 mil hectares. O Estado de São Paulo configura-se como o maior produtor do Brasil, com produção de 308.966 toneladas (IBGE, 2016).

O tangor 'Murcott' (Citrus reticulata Blanco $\times$ Citrus sinensis (L.) Osbeck) e a tangerina 'Ponkan' são importantes variedades cultivadas no Estado de São Paulo, concentrando-se, nessas duas variedades, boa parte da produção de tangerinas e híbridos (PIO et al., 2006; NASCIMENTO et al., 2011). O tangor 'Murcott' se destaca pela qualidade da polpa. Seu suco possui sabor intenso, é mais doce e mais alaranjado do que o suco da tangerina 'Ponkan'. Devido a estas características, pode ser utilizado tanto para indústria de suco quando para comercialização in natura. Por outro lado, possui elevada quantidade de sementes e sua casca é fina e bem aderida à polpa. Assim, a oferta deste fruto minimamente processado pode ser uma opção atraente para ampliar seu consumo in natura.

O mercado dos produtos minimamente processados encontra-se em franca expansão, pois permite a oferta de produtos frescos, convenientes, com segurança microbiológica e boa qualidade sensorial (IUAMOTO et al., 2015; KLUGE et al., 2014), tanto no segmento de varejo quanto em cozinhas industriais. No entanto, quando um fruto é submetido ao processamento, como o corte (metades, tiras e/ou cubos), a sua proteção externa é removida, tornando-o mais susceptível ao ataque de microrganismos patogênicos e à deterioração microbiana, em comparação com o fruto íntegro (OMS-OLIU et al., 2010).

Por isso, faz-se necessária a utilização de etapas, como sanificação, centrifugação e drenagem. Na sanificação, geralmente são utilizados produtos clorados, pois são eficientes na manutenção da segurança alimentar, possuem baixo custo e podem ser implementados em operações de qualquer tamanho, sendo bastante importante no papel da minimização da deterioração (PHUA et al., 2014; SREBERNICH, 2007). A centrifugação - ou a drenagem é especialmente importante para a retirada do excesso de água presente no fruto em decorrência do enxágue e da própria sanificação. Dessa forma, é importante que a água absorvida nas etapas de sanificação e enxague seja retirada, a fim de minimizar a ocorrência de contaminação microbiológica e/ou prejudicar a aparência (MORETTI; MATTOS, 2011).

Diante disso, este trabalho teve como objetivo determinar tipos de corte e métodos de sanificação e de eliminação do excesso de líquidos no processamento mínimo de tangor 'Murcott'.

\section{Material e métodos}

Tangores 'Murcott' (Citrus reticulata Blanco $\times$ Citrus sinensis (L.) Osbeck) foram colhidos em pomares comerciais, no município de Urânia, a 460 km de Piracicaba-SP, no estádio de maturação comercial, sendo então submetidos a beneficiamento cuidadoso, de forma a obter frutos lavados, selecionados de acordo com a coloração da casca e sem danos mecânicos. Em seguida, foram transportados para o Laboratório de Pós-colheita de Produtos Hortícolas do Departamento de Produção Vegetal da Escola Superior de Agricultura "Luiz de Queiroz" (ESALQ/USP), em Piracicaba-SP, onde foram novamente selecionados, lavados e sanificados em solução com $200 \mathrm{mg} \mathrm{L}^{-1}$ de cloro ativo por dez minutos e resfriados a $6{ }^{\circ} \mathrm{C}$ por 12 horas. Os frutos resfriados foram submetidos ao descascamento hidrotérmico, conforme Arruda et al. (2008), que consiste na imersão em água a $50^{\circ} \mathrm{C}$ por oito minutos, seguido de descascamento manual.

Os frutos sem albedo e sem flavedo foram, então, avaliados quanto aos tipos de corte e aos métodos de sanificação e de eliminação do excesso de líquidos, em dois experimentos.

\subsection{Experimento 1: Tipos de cortes}

Os frutos foram submetidos a três tipos de corte, conforme descritos a seguir: 1) Metades: foram submetidos a dois cortes paralelos, que dividiram cada fruto em três partes, sendo um disco central contendo a columela e duas metades. $O$ disco central foi descartado e as metades foram aproveitadas. 2) Tiras: cada uma das metades foi submetida a dois cortes longitudinais paralelos, dando origem a três tiras. Mais duas tiras foram obtidas das laterais do disco que contém a columela central, totalizando oito tiras com dimensões semelhantes. 3) Cubos: cada uma das tiras foi subdividida em três partes, de forma que cada fruto originou 24 pedaços com dimensões semelhantes.

Os frutos cortados foram acondicionados em bandejas plásticas rígidas de politereftalato de etila (PET), com $200 \mathrm{~g}$ de produto cada, armazenados em câmara a $5{ }^{\circ} \mathrm{C}$ durante 12 dias, e analisados a cada três dias quanto a: a) ácido ascórbico (AA): determinado por titulometria, de acordo com metodologia descrita por Carvalho et al. (1990), e os resultados foram expressos em miligrama de ácido ascórbico por $100 \mathrm{~g}$ de polpa; b) teor de sólidos solúveis (SS): leitura direta em refratômetro digital, sendo os resultados expressos em porcentagem, segundo metodologia da AOAC (LATIMER JUNIOR, 2012); c) acidez titulável (AT): determinada de acordo com metodologia descrita por Carvalho et al. (1990) e os resultados foram expressos em porcentagem de ácido cítrico na polpa; d) relação SS/AT: calculada pela divisão dos teores de SS pelos de AT; e) extravasamento de líquidos: medido por diferença entre a massa inicial da bandeja com os frutos 
no dia de análise e a massa da bandeja com os frutos depois de drenado o suco extravasado, descontando-se a massa da bandeja. Os resultados foram expressos em porcentagem; f) rendimento em produto minimamente processado: razão entre a massa do produto após o processamento mínimo e a massa inicial do fruto na forma íntegra, sendo avaliada para cada tipo de corte e expressa em porcentagem; g) análise sensorial de aparência: foi utilizado o teste de aceitabilidade, por meio do qual o produto minimamente processado de cada tratamento foi oferecido a 30 provadores não treinados, nas próprias embalagens. As notas foram atribuídas com base numa escala hedônica balanceada de nove pontos, em que $9=$ gostei muitíssimo, $8=$ gostei muito, $7=$ gostei moderadamente, 6=gostei ligeiramente, 5=indiferente, 4 =desgostei ligeiramente, $3=$ desgostei moderadamente, 2 =desgostei muito e 1=desgostei muitíssimo. Com base nos resultados, escolheu-se o melhor tipo de corte, o qual foi estudado na fase seguinte.

\subsection{Experimento 2: Métodos de sanificação e de eliminação do excesso de líquidos}

Os métodos de sanificação com cloro foram baseados nas recomendações de Donadon et al. (2004) e consistiram em: a) sanificação em solução com $20 \mathrm{mg} \mathrm{L}^{-1}$ de cloro ativo a $5{ }^{\circ} \mathrm{C}$, por dez minutos, após o corte; b) enxágue em água a $5{ }^{\circ} \mathrm{C}$ após o corte para retirada do suco extravasado, seguido de sanificação em solução com $100 \mathrm{mg} \mathrm{L}^{-1}$ de cloro ativo a $5^{\circ} \mathrm{C}$, por dez minutos, e um segundo enxágue em solução com $10 \mathrm{mg} \mathrm{L}^{-1}$ de cloro ativo a $5^{\circ} \mathrm{C}$. Para produzir as concentrações desejadas de cloro ativo, utilizou-se dicloroisocianurato de sódio di-hidratado (Sumaveg, Johnson-Diversey Brasil Ltda.).

Os métodos de eliminação do excesso de líquidos foram: a) drenagem em escorredor doméstico por um minuto; b) centrífuga doméstica Arno, com velocidade de $760 \times$ g, por cinco segundos; c) centrífuga doméstica Arno, com velocidade de $760 \times$ g, por dez segundos.

Frutos não sanificados e sem eliminação do excesso de líquido foram utilizados como controle. Frutos de todos os tratamentos foram acondicionados em bandejas PET, armazenados a $5^{\circ} \mathrm{C}$ durante 12 dias, e analisados a cada seis dias quanto a:

a) Extravasamento de líquidos: foi utilizada a mesma metodologia do Experimento 1

b) Análise sensorial de aparência: foi realizada com o objetivo de identificar os efeitos dos métodos de eliminação do excesso de líquidos na aparência do produto minimamente processado. Foram avaliados os tratamentos controle, drenagem e centrifugação, todos sem sanificação. Os tratamentos foram oferecidos aos provadores nas próprias embalagens, contendo $200 \mathrm{~g}$ do produto minimamente processado. As notas foram atribuídas com base numa escala hedônica balanceada de cinco pontos, na qual $5=$ gostei muito, 4=gostei moderadamente, 3=indiferente, 2=desgostei moderadamente e 1=desgostei muito.

c) Análise sensorial de sabor: foi realizada com o objetivo de identificar os efeitos dos métodos de sanificação com cloro no sabor do produto minimamente processado. Foram avaliados os seguintes tratamentos: sanificação com $20 \mathrm{mg} \mathrm{L}^{-1}$ de cloro ativo, sanificação com $100 \mathrm{mg} \mathrm{L}^{-1}$ de cloro ativo seguida de enxágue em solução com $10 \mathrm{mg} \mathrm{L}^{-1}$ de cloro ativo e o controle. Utilizou-se o teste da diferença do controle com 30 provadores não treinados. Foram oferecidas amostras de aproximadamente 50 gramas do produto minimamente processado, de cada tratamento. No teste da diferença do controle, o provador comparou uma amostra padrão com duas amostras codificadas, avaliando o grau de diferença entre estas e atribuiu-lhes notas. Neste teste, foi utilizada uma escada de 1 a 5 , em que 1=nenhuma diferença, 2=pouca diferença, 3=média diferença, 4=muito diferente e $5=$ extremamente diferente.

d) Análise microbiológica: foram realizadas análises para contagem total de bactérias psicrotróficas, contagem de bolores e leveduras, número mais provável de coliformes totais e número mais provável de coliformes a $45^{\circ} \mathrm{C}$, de acordo com os métodos propostos por Silva et al. (2007).

O delineamento de cada experimento foi inteiramente aleatorizado, em esquema fatorial (tratamento $x$ dias de análise), sendo que cada tratamento foi constituído de seis repetições. Cada repetição foi composta por uma bandeja contendo aproximadamente $200 \mathrm{~g}$ de tangor 'Murcott' minimamente processado. Os dados foram analisados estatisticamente e as médias foram comparadas pelo teste de Tukey com probabilidade de erro de $5 \%$, utilizando SAS 9.3 software (SAS INSTITUTE, 2010).

\section{Resultados e discussão}

\subsection{Experimento 1: tipos de corte}

O teor de ácido ascórbico (AA) do tangor 'Murcott'

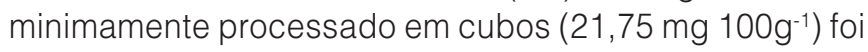

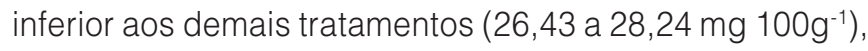
ao final do armazenamento (Tabela 1). Silva et al.

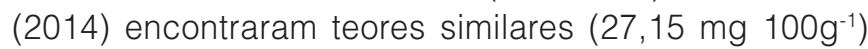
avaliando a qualidade de tangerinas 'Ponkan'. O AA é uma substância redutora que pode ser facilmente oxidada quando exposta a calor, luz e oxigênio, pH alcalino ou 
Processamento mínimo de tangor 'Murcott': tipos de corte, sanificação e eliminação do excesso de líquidos

Chiarini, R. F. et al.

enzimas (ODRIOZOLA-SERRANO et al., 2007). O corte em cubos é o que provoca maior exposição dos tecidos e do suco das vesículas e, portanto, maior superfície de contato com o ar, podendo, com isso, resultar em maior perda de AA. Apesar de o corte em tiras apresentar maior superfície exposta em relação ao corte em metades, não ocorreram diferenças significativas em relação ao AA, como no tratamento em cubos (Tabela 1).

Segundo Carnelossi et al. (2004), alguns frutos cítricos e hortaliças podem apresentar retenção ou aumento nos teores de vitamina $\mathrm{C}$ quando armazenados. Sugere-se que o aumento pode estar relacionado à atuação da vitamina $\mathrm{C}$ como antioxidante, em resposta ao avanço das reações oxidativas que ocorrem durante o amadurecimento.

Não foram observadas diferenças nos teores de sólidos solúveis em função dos tratamentos e do tempo de armazenamento (Tabela 1). Os teores variaram de 11,59 a $12,80 \%$, no presente estudo. Comportamento similar foi relatado por Chaudhary et al. (2016), analisando frutos de citros da cultivar Rio Red (Citrus paradisi Macf), cujos valores se mantiveram constantes durante 12 dias a $5{ }^{\circ} \mathrm{C}$. Nascimento et al. (2011), ao avaliarem tangerinas W Murcott armazenadas em ambiente refrigerado por
90 dias, encontraram teores similares $(11,65 \%)$ aos obtidos neste estudo.

Houve redução no teor de acidez titulável (AT) durante o armazenamento. Os teores mais elevados de AT foram verificados nos cortes em metades $(0,56 \%$ de ácido cítrico) e em tiras $(0,49 \%)$ (Tabela 1$)$. Nos frutos submetidos ao corte em cubos, os teores foram de $0,44 \%$ de ácido cítrico. Uma razão para esse comportamento distinto entre os tipos de cortes é que, nos frutos submetidos ao corte em metades e em tiras, a degradação dos ácidos orgânicos ocorreu, provavelmente, de forma menos acentuada no que no tratamento em cubos.

Durante o armazenamento, a concentração de ácidos orgânicos diminui devido à utilização no ciclo de Krebs, isto é, na produção de coenzimas reduzidas, substratos para produção de ATP, como parte do fornecimento energético às atividades metabólicas dos frutos (OMS-OLIU et al., 2011). Portanto, a maior incidência de injúrias, causada pelo maior número de cortes durante o processamento mínimo em cubos, pode acelerar o metabolismo vegetal e acentuar o consumo de ácidos orgânicos.

A relação SS/AT aumentou como consequência da redução da acidez (Tabela 1). Os valores foram de 22,05 no início do armazenamento para 22,96; 25,55; 27,70, para

Tabela 1. Teores de ácido ascórbico (AA), sólidos solúveis (SS), acidez titulável (AT), relação entre sólidos solúveis e acidez titulável (SS/AT) e extravasamento de suco (ES) em tangor 'Murcott' minimamente processado, armazenado a $5{ }^{\circ} \mathrm{C}$.

\begin{tabular}{|c|c|c|c|c|c|}
\hline \multicolumn{6}{|c|}{ Dias de armazenamento } \\
\hline \multirow{2}{*}{ Tipos de corte } & 0 & 3 & 6 & 9 & 12 \\
\hline & \multicolumn{5}{|c|}{ AA $\left(m g 100 g^{-1}\right)$} \\
\hline Metades & $28,66^{a *}$ & $23,84 \mathrm{cA}$ & 25,00 bcA & 24,73 bcA & 28,24 abA \\
\hline Tiras & $28,66^{\text {aA }}$ & $24,29 \mathrm{bA}$ & 24,01 bA & 24,38 bA & 26,43 abA \\
\hline Cubos & $28,66^{\text {aA }}$ & 23,86 bA & 24,01 bA & 22,98 bB & $21,75 \mathrm{bB}$ \\
\hline \multicolumn{6}{|c|}{ SS (\%) } \\
\hline Metades & $12,67^{a}$ & $12,41^{\text {a }}$ & $12,09^{a}$ & $12,31^{a}$ & $12,80^{a}$ \\
\hline Tiras & $12,67^{a}$ & $12,30^{a}$ & $11,94^{a}$ & $12,40^{a}$ & $12,51^{a}$ \\
\hline Cubos & $12,67^{a}$ & $11,93^{\text {a }}$ & $12,04^{a}$ & 11,59 a & $12,03^{a}$ \\
\hline \multicolumn{6}{|c|}{ AT (\% de ácido cítrico) } \\
\hline Tratamento & 0 dias & 3 dias & 6 dias & 9 dias & 12 dias \\
\hline Metades & 0,58 aA & 0,53 aA & 0,48 aA & 0,52 aA & 0,56 aA \\
\hline Tiras & $0,58^{\mathrm{aA}}$ & $0,55^{\mathrm{aA}}$ & 0,49 aA & $0,51^{\text {aA }}$ & 0,49 aAB \\
\hline Cubos & $0,58 \mathrm{aA}$ & 0,59 aA & 0,51 abA & 0,43 bB & $0,44 \mathrm{bB}$ \\
\hline \multicolumn{6}{|c|}{ SS/AT } \\
\hline Tratamento & 0 dias & 3 dias & 6 dias & 9 dias & 12 dias \\
\hline Metades & 22,05 aA & 23,36 abB & 25,34 bA & $23,95 \mathrm{abA}$ & $22,96 \mathrm{abA}$ \\
\hline Tiras & $22,05^{a A}$ & $22,53^{\mathrm{aAB}}$ & 24,24 abA & $24,35 \mathrm{abA}$ & 25,55 bAB \\
\hline Cubos & $22,05 \mathrm{abA}$ & 20,48 aA & 24,07 bA & 27,05 cB & $27,70 \mathrm{cB}$ \\
\hline \multicolumn{6}{|c|}{ ES (\%) } \\
\hline Tratamento & 3 dias & 6 dias & 9 dias & 12 dias & \\
\hline Metades & $0,00 \mathrm{Aa}$ & 0,00 aA & 0,00 aA & 0,00 aA & \\
\hline Tiras & 0,30 aA & 0,67 abB & 0,32 aA & 0,28 aA & \\
\hline Cubos & $1,10 \mathrm{aB}$ & $1,55 \mathrm{bc}$ & $1,27 \mathrm{bB}$ & $1,48 \mathrm{bB}$ & \\
\hline
\end{tabular}

*Médias seguidas da mesma letra minúscula na linha e maiúscula na coluna não diferem entre si pelo teste Tukey, a $5 \%$ de probabilidade. 
Processamento mínimo de tangor 'Murcott': tipos de corte, sanificação e eliminação do excesso de líquidos

Chiarini, R. F. et al.

os cortes em metades, tiras e cubos, respectivamente, ao final do armazenamento. Segundo Berilli et al. (2011), essa relação pode ser a expressão dos teores de SS e AT mais indicada para correlacionar esses parâmetros com a percepção da doçura e da acidez sensorial.

O extravasamento de suco foi maior no tratamento de corte em cubos. Isso pode ter ocorrido devido à maior área de superfície exposta nesse formato de corte, causando maior perda de compartimentação celular. Uma alta porcentagem de extravasamento de suco compromete a aparência do produto, pois quanto maior o extravasamento do suco celular, maior a desidratação do produto (KLUGE et al., 2006). Os frutos cortados em metades e em tiras apresentaram quantidades baixas de suco extravasado na bandeja, demonstrando uma vantagem desses tipos de corte perante o de cubos.

Com relação ao rendimento (Figura 1), foi verificado que o corte em metades forneceu menor rendimento $(44,7 \%)$. Isso pode ter ocorrido devido à maior quantidade de polpa descartada no disco central, juntamente com a columela. Já os cortes em tiras apresentaram rendimento de $64,9 \%$ e os cortes em cubos, $63,1 \%$. Acredita-se que isso ocorreu em função do aproveitamento da parte do disco central, sendo descartada apenas uma pequena porção contendo a columela central.

Souza et al. (2005), analisando os diferentes tipos de corte em mamão 'Formosa' minimamente processado, encontraram rendimento de $88,1 \%$ no corte em metades e $66,2 \%$ no corte em fatias. Por outro lado, Cardoso et al. (2010), avaliando o rendimento de diversos frutos para produção de saladas de frutas, obtiveram valores de $67 \%$ para o mamão, 62\% para a manga, 44\% para o maracujá, 47\% para a goiaba e $62 \%$ para a banana. Apenas o rendimento de mamão foi superior ao relatado no presente trabalho. Segundo os mesmos autores, o conhecimento acerca do rendimento é muito importante para a indústria, pois assim é possível estimar a produtividade,

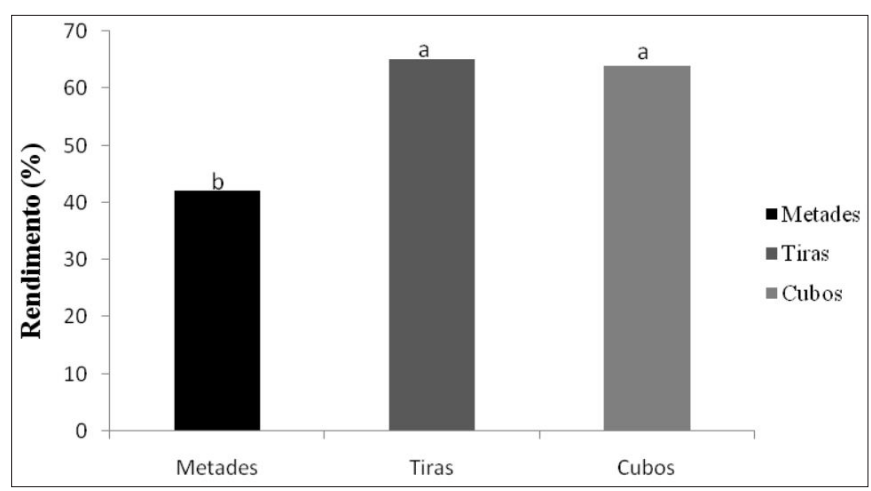

Figura 1. Rendimento (\%) de tangor 'Murcott' minimamente processado em função dos tipos de corte (médias seguidas da mesma letra não diferem entre si pelo teste Tukey, a 5\% de probabilidade). as perdas e também o custo de produção e de venda do produto final.

O corte em tiras apresentou a maior aceitabilidade no atributo aparência, com notas entre 'gostei muito' e 'gostei moderadamente'. O tratamento em metades apresentou notas medianas que ficaram entre 'gostei moderadamente' a 'gostei ligeiramente'. Os provadores mencionaram como inconvenientes a presença de sementes e o tamanho grande, pouco apropriado para o consumo imediato. O corte em cubos agradou os provadores no início do armazenamento, mas, no decorrer do armazenamento, as notas decaíram, apresentando, de forma geral, a menor aceitabilidade dentre os tipos de corte (Figura 2). Segundo relatado por alguns provadores, o corte em cubos apresentava os inconvenientes de acumular suco no fundo da bandeja e de aspecto de "passado" ou "resto", por ser demasiadamente picado.

Groppo et al. (2009), avaliando Iaranja 'Pera' minimamente processada, reportaram notas de aparência semelhantes às encontradas no presente estudo para o corte em cubos. O tangor minimamente processado submetido ao corte em cubos apresentou maior extravasamento de suco e menores notas de aparência.

O corte em cubos apresentou resultados inferiores aos demais tratamentos quanto à qualidade físico-química, ao extravasamento de suco e às notas de aparência. $\mathrm{O}$ corte em metades apresentou baixo rendimento em produtos minimamente processados. O corte em tiras apresentou resultados iguais ou superiores aos demais tratamentos, com destaque para a aceitabilidade, em termos de aparência, sendo que, nesse parâmetro, este tratamento foi superior aos demais. Assim, o corte em tiras foi escolhido para os estudos de sanificação e eliminação do excesso de líquidos.

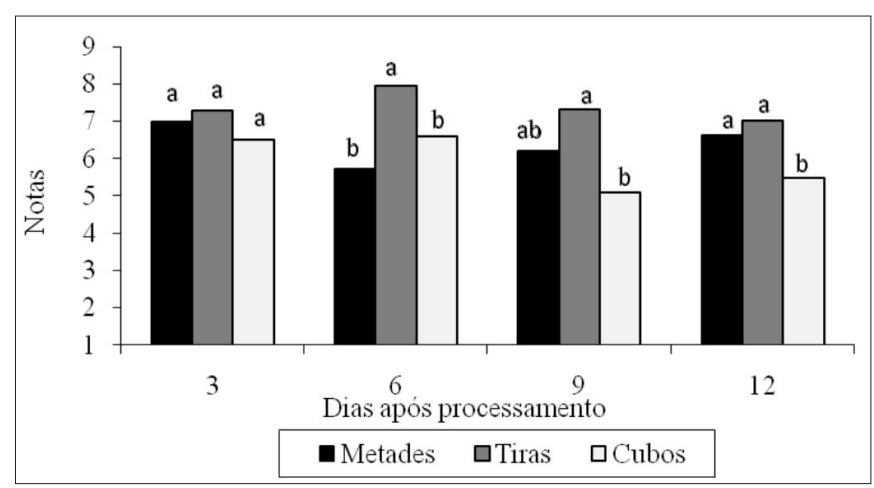

Figura 2. Aparência de tangor 'Murcott' minimamente processado em três tipos de corte, armazenado a $5^{\circ} \mathrm{C}$ (Notas com base em escala hedônica, em que $9=$ gostei muitíssimo, $8=$ gostei muito, 7 =gostei moderadamente, $6=$ gostei ligeiramente, $5=$ indiferente, 4 =desgostei ligeiramente, 3 =desgostei moderadamente, 2=desgostei muito e 1=desgostei muitíssimo. Médias seguidas da mesma letra não diferem entre si pelo teste Tukey, a 5\% de probabilidade, em cada dia de análise). 
Processamento mínimo de tangor 'Murcott': tipos de corte, sanificação e eliminação do excesso de líquidos Chiarini, R. F. et al.

\subsection{Métodos de sanificação e de eliminação do excesso de líquidos}

Os métodos de eliminação do excesso de líquidos foram eficientes na redução do acúmulo de líquido extravasado. Observam-se valores numericamente menores nos tratamentos em que foi utilizada a centrifugação do que naqueles do controle ou com drenagem. Esta diferença pode ser comprovada estatisticamente em alguns tratamentos no sexto dia de armazenamento (Tabela 2). No $12 .^{\circ}$ dia de armazenamento, ficou evidenciada a diferença entre o controle e os demais tratamentos.

Iuamoto et al. (2015), avaliando a quantidade de extravasamento de suco em frutos de laranja 'Pera' minimamente processada, durante um período de 12 dias, observaram que a menor quantidade de extravasamento de suco ocorreu naqueles frutos em que se utilizou a centrifugação. Quando ocorre maior extravasamento de suco, indica-se que o produto minimamente processado poderá ser submetido a uma nova sanificação, pois este se torna, possivelmente, uma fonte de inóculo. No entanto, quando não ocorre o extravasamento de suco, essa operação pode ser desnecessária.

Os sistemas de eliminação do excesso de líquidos (drenagem e centrifugação) afetaram a aparência do produto minimamente processado imediatamente após o processamento. O controle recebeu nota superior aos demais tratamentos no primeiro dia de análise, mas, a partir do sexto dia, não foram observadas diferenças entre os tratamentos (Figura 3).

A diferença no primeiro dia pode ser justificada pelo maior brilho neste tratamento, conforme comentários dos provadores. Nos demais dias, não se observaram comentários comuns sobre este aspecto, o que sugere que esta característica foi anulada com o tempo. Durante o armazenamento, as notas dos provadores se mantiveram constantes, por volta de 3,5, não havendo diferença entre os tratamentos e nem destes com o controle.

As duas doses de sanificação (20 e $100 \mathrm{mg} \mathrm{L}^{-1}$ de cloro ativo) não alteraram o sabor do tangor 'Murcott' minimamente processado durante o período de armazenamento. As notas de sabor variaram de 2,0 a 2,5, numa escala em que nota 2,0 significa pouca diferença e nota 3,0 indica média diferença, em relação ao controle. Esse comportamento foi verificado durante todo o armazenamento (Figura 4).

Os tratamentos submetidos à centrifugação apresentaram os maiores níveis de contaminação para a contagem total de bactérias psicrotróficas $\left(1,6 \times 10^{3}\right)$ e para a contagem total de bolores e leveduras $\left(2,9 \times 10^{3}\right)$. Isso pode ter ocorrido porque talvez o tempo utilizado no processo não tenha sido suficiente para total retirada da água do produto minimamente processado (CARNELOSSI et al., 2005). Por outro lado, para o tratamento com sanificação (100 mg L $\left.{ }^{-1}\right)$ + enxágue + centrifugação, a CTBP e a CTBL foram baixas, com valores menores que dez $(<10)$, no sexto dia de armazenamento, e $5 \times 10$, no $12^{\circ}$ dia de armazenamento. (Tabela 3). Estes resultados corroboram com os obtidos por Donadon et al. (2004) e Pinheiro et al. (2009), que verificaram baixos níveis de contaminação microbiológica pelos métodos de contagem total de bactérias psicrotróficas (CTBP) e de contagem total de bolores e leveduras (CTBL) em laranjas minimamente processadas.

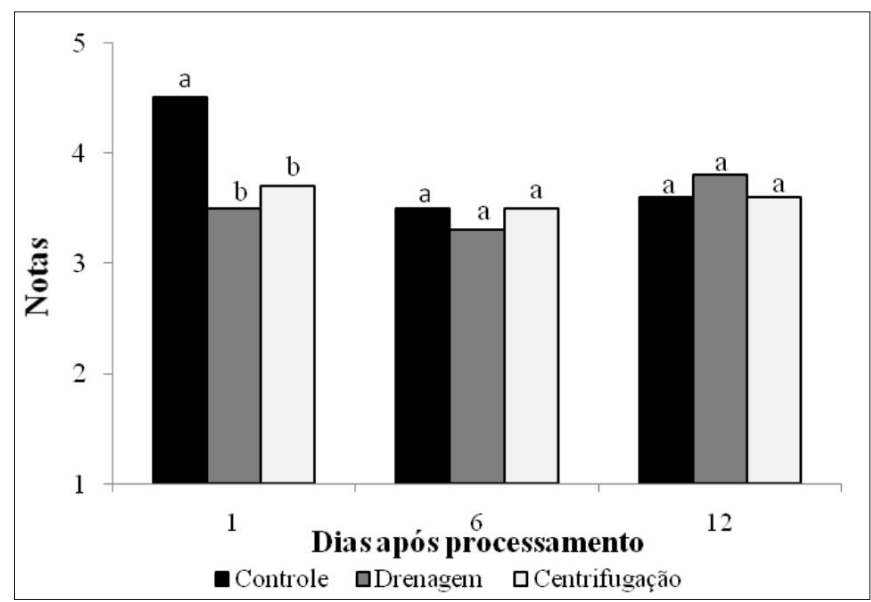

Figura 3. Aparência de tangor 'Murcott' minimamente processado em função dos métodos de eliminação do excesso de líquidos, armazenado a $5{ }^{\circ} \mathrm{C}$ (Notas com base em escala hedônica, em que $5=$ gostei muito, 4=gostei moderadamente, $3=$ indiferente, $2=$ desgostei moderadamente e 1=desgostei muito. Médias seguidas de letras diferentes diferem entre si pelo teste Dunnett, a $5 \%$ de probabilidade, em cada dia de análise).

Tabela 2. Extravasamento de suco (\%) em tangor 'Murcott' minimamente processado em função dos métodos de sanificação e de eliminação do excesso de líquidos, armazenado a $5{ }^{\circ} \mathrm{C}$.

\begin{tabular}{|c|c|c|}
\hline Tratamento & 6 dias & 12 dias \\
\hline Controle & 0,47 aA & $1,15^{\mathrm{bA}}$ \\
\hline Drenagem & 0,40 aAB & $0,23 \mathrm{aBC}$ \\
\hline Centrifugação & $0,04 \mathrm{ac}$ & $0,07 \mathrm{aBC}$ \\
\hline Sanificação $\left(20 \mathrm{mg} \mathrm{L}^{-1}\right)+$ Drenagem & 0,22 aABC & $0,17 \mathrm{aBC}$ \\
\hline Sanificação (20 mg L-1) + Centrifugação & $0,03 \mathrm{ac}$ & $0,05 \mathrm{aBC}$ \\
\hline Sanificação (100 mg L-1) + Enxágue + Drenagem & $0,54^{\text {aA }}$ & 0,39 aв \\
\hline Sanificação (100 mg L-1) + Enxágue + Centrifugação & 0,06 aBC & $0,03 \mathrm{ac}$ \\
\hline
\end{tabular}

Médias seguidas da mesma letra minúscula na linha e maiúscula na coluna não diferem entre si pelo teste Tukey, a $5 \%$ de probabilidade. 
Processamento mínimo de tangor 'Murcott': tipos de corte, sanificação e eliminação do excesso de líquidos Chiarini, R. F. et al.

Tabela 3. Contagem total de bactérias psicrotróficas (CTBP) e contagem total de bolores e leveduras (CTBL) em tangor 'Murcott' minimamente processado em tiras, armazenado a $5^{\circ} \mathrm{C}$.

\begin{tabular}{|c|c|c|}
\hline \multicolumn{3}{|c|}{ Contagem total de bactérias psicrotróficas (CTBP) } \\
\hline Tratamento & Dia 6 & Dia 12 \\
\hline Controle & $<10$ & $4,0 \times 10$ \\
\hline Drenagem & $<10$ & $<10$ \\
\hline Centrifugação & $<10$ & $1,6 \times 10^{3}$ \\
\hline Sanificação (20 mg L-1) + Drenagem & $1,0 \times 10$ & $<10$ \\
\hline Sanificação (20 mg L-1) + Centrifugação & $<10$ & $<10$ \\
\hline Sanificação (100 mg L-1) + Enxágue + Drenagem & $2,0 \times 10$ & $5,0 \times 10$ \\
\hline Sanificação (100 mg L-1) + Enxágue + Centrifugação & $<10$ & $<10$ \\
\hline \multicolumn{3}{|c|}{ Contagem total de bolores e leveduras (CTBL) } \\
\hline Tratamento & Dia 6 & Dia 12 \\
\hline Controle & $3,0 \times 10$ & $4,0 \times 10$ \\
\hline Drenagem & $1,0 \times 10$ & $<10$ \\
\hline Centrifugação & $<10$ & $2,9 \times 10^{3}$ \\
\hline Sanificação $\left(20 \mathrm{mg} \mathrm{L}^{-1}\right)+$ Drenagem & $1,0 \times 10$ & $1,2 \times 10^{2}$ \\
\hline Sanificação (20 mg L-1) + Centrifugação & $4,0 \times 11$ & $3,0 \times 10^{2}$ \\
\hline Sanificação (100 mg L-1) + Enxágue + Drenagem & $1,0 \times 10^{2}$ & $1,0 \times 10^{2}$ \\
\hline Sanificação (100 mg L-1) + Enxágue + Centrifugação & $<10$ & $5,0 \times 10$ \\
\hline
\end{tabular}

Os resultados obtidos são expressos em UFC (unidades formadoras de colônia/g de produto).

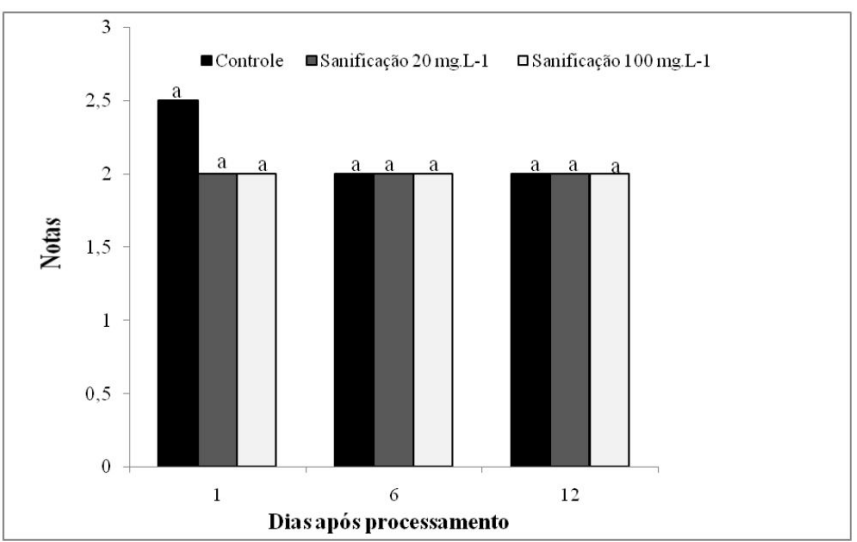

Figura 4. Sabor de tangor 'Murcott' minimamente processado, em função da sanificação, armazenado a $5{ }^{\circ} \mathrm{C}$ (Notas com base em escala sensorial pelo teste de diferença do controle, com 5 pontos, em que 1= significa nenhuma diferença, $2=$ pouca diferença, $3=$ média diferença, $4=$ muito diferente $\mathrm{e}$ $5=$ extremamente diferente. Médias seguidas da mesma letra não diferem entre si pelo teste Dunnett, a 5\% de probabilidade, em cada dia de análise).

Não foram detectados coliformes totais e nem coliformes a $45^{\circ} \mathrm{C}$, nas amostras analisadas no presente estudo. Provavelmente, as características intrínsecas do fruto ( $\mathrm{pH}$ baixo) e as boas técnicas de fabricação contribuíram para estes resultados positivos. Do mesmo modo, Groppo et al. (2009) não detectaram contaminação por coliformes a $45^{\circ} \mathrm{C}$ em amostras de laranjas minimamente processadas, durante o armazenamento de 12 dias.

A resolução RDC n. ${ }^{\circ} 12$ de 2 de janeiro de 2001 da Agência Nacional de Vigilância Sanitária do Ministério da Saúde (BRASIL, 2001) estabelece que frutas frescas preparadas (descascadas, selecionadas ou fracionadas) devem ter, no máximo, $5 \times 10^{2} \mathrm{NMP}$ de coliformes a $45^{\circ} \mathrm{C} \mathrm{g}^{-1}$ e devem ter ausência de Salmonella em $25 \mathrm{~g}$ de produto.

Em relação a coliformes totais e contagens totais de bactérias e de bolores e leveduras, não há limites máximos estabelecidos pela legislação, porém é preconizado que alimentos contendo contagens da ordem de $10^{4} \mathrm{e}^{10^{5}} \mathrm{UFC} \mathrm{g}^{-1}$ são impróprios para o consumo humano devido à perda do valor nutricional, às alterações sensoriais, aos riscos de deterioração e/ou presença de patógenos (SREBERNICH, 2007; ARRUDA et al., 2011). Os níveis de contaminação por bactérias anaeróbias e psicrotróficas e por bolores e leveduras em tangor 'Murcott' minimamente processado foram inferiores a $10^{4}$ ou $10^{5} \mathrm{em}$ todos os tratamentos. Dessa forma, todos os tratamentos poderiam ser indicados para o consumo.

\section{Conclusões}

O corte em tiras é mais recomendado para o processamento mínimo de tangor 'Murcott', quando comparado aos cortes em metades ou cubos.

As operações de sanificação e de eliminação do excesso de líquidos não afetaram a aparência e nem o sabor; portanto, mostraram-se dispensáveis no processamento mínimo de tangor 'Murcott', em tiras, nas condições do presente estudo.

A centrifugação como método de eliminação do excesso de líquidos em tangor 'Murcott' minimamente processado deve ser associada à sanificação. 
Processamento mínimo de tangor 'Murcott': tipos de corte, sanificação e eliminação do excesso de líquidos Chiarini, R. F. et al.

\section{Referências}

ARRUDA, M. C. D.; JACOMINO, A. P.; PINHEIRO, A. L.; RIBEIRO, R. V.; LOCHOSKI, M. A.; MOREIRA, R. C. Hydrothermal treatment favors peeling of 'Pera' sweet orange fruit Hydrothermal treatment favors peeling of 'Pera' sweet orange fruit and does not alter quality. Scientia Agricola, Piracicaba, v. 65, n. 2, p. 151-156, 2008. http://dx.doi.org/10.1590/S0103-90162008000200007.

ARRUDA, M. C.; JACOMINO, A. P.; TREVISAN, M. J.; JERONIMO, E. M.; MORETTI, C. L. Atmosfera modificada em laranja 'Pêra' minimamente processada. Bragantia, Campinas, v. 70, n. 3, p. 664-671, 2011. http://dx.doi.org/10.1590/S0006-87052011000300023.

BERILLI, S. S.; BERILLI, A.; FREITAS, S.; SANTOS, P.; ALMEIDA, S.; CARVALHO, A. Avaliação sensorial dos frutos de cultivares de abacaxi para consumo in natura. Revista Brasileira de Fruticultura, Jaboticabal, v. 33, n. spe1, p. 592-598, 2011. http:// dx.doi.org/10.1590/S0100-29452011000500081.

BRASIL. Agência Nacional de Vigilância Sanitária. Resolução RDC n 12 de 02 de janeiro de 2001. Dispõe sobre o Regulamento técnico sobre padrões microbiológicos para alimentos. Diário Oficial [da] República Federativa do Brasil, Brasília, DF, 10 jan. 2001

CARDOSO, W. S.; PINHEIRO, F. A.; PEREZ, R.; PATELLI, T.; FARIA, E. R. Desenvolvimento de uma salada de frutas: da pesquisa de mercado à tecnologia de alimentos. Ciência e Tecnologia de Alimentos, Campinas, v. 30, n. 2, p. 454-462, 2010. http:// dx.doi.org/10.1590/S0101-20612010000200024.

CARNELOSSI, M. A. G.; TOLEDO, W. F. F.; SOUZA, D. C. L.; LIRA, M. D. L.; SILVA, G. D.; JALALI, V. R. R.; VIÉGAS, P. D. A. Conservação pós-colheita de mangaba (Hancornia speciosa Gomes). Ciência e Agrotecnologia, Lavras, v. 28, n. 5, p. 11191125, 2004. http://dx.doi.org/10.1590/S1413-70542004000500021.

CARNELOSSI, M. A. G.; YAGUIU, P.; REINOSO, A. C. L.; ALMEIDA, G. R. D. O.; LIRA, M. L.; SILVA, F. G.; JALALI, V. R. Determinação das etapas do processamento mínimo de quiabo. Horticultura Brasileira, Brasília, v. 23, n. 4, p. 970-975, 2005. http://dx.doi. org/10.1590/S0102-05362005000400022

CARVALHO, C. R. L.; MANTOVANI, D. M. B.; CARVALHO, P. R. N.; MORAES, R. M. M. Análise química de alimentos. Campinas: ITAL, 1990. $121 \mathrm{p}$.

CHAUDHARY, P. R.; YU, X.; JAYAPRAKASHA, G. K.; PATIL, B. S. Influence of storage temperature and low temperature conditioning on the levels of health promoting compounds in Rio Red grapefruit. Food Science \& Nutrition, Australia, 2016. No prelo.

DONADON, J. R.; DURIGAN, J. F.; SOUZA, B. S. D.; TEIXEIRA, G. H. D. A.; SANCHES, J. Efeito do tipo de descasque e da temperatura de armazenamento na qualidade de laranjas 'Pêra' minimamente processadas. Revista Brasileira de Fruticultura, Jaboticabal, v. 26, n. 3, p. 419-423, 2004. http://dx. doi.org/10.1590/ S0100-29452004000300012.
GROPPO, V. D.; SPOTO, M. H. F.; GALLO, C. R.; SARMENTO, S. B. S. Efeito do cloreto de cálcio e da película de alginato de sódio na conservação de laranja 'Pera'minimamente processada. Ciência e Tecnologia de Alimentos, Campinas, v. 29, n. 1, p. 107-113, 2009. http://dx.doi.org/10.1590/S0101-20612009000100017.

INSTITUTO BRASILEIRO DE GEOGRAFIA E ESTATÍSTICA - IBGE. Rio de Janeiro, 2016. Disponível em: <http://www.ibge.gov.br>. Acesso em: 10 jul. 2016.

IUAMOTO, M. Y.; JACOMINO, A. P.; MATTIUZ, C. F. M.; SILVA, A. P. G.; KLUGE, R. A.; ARRUDA-PALHARINI, M. C. Sanificação e eliminação do excesso de líquidos em laranja 'Pêra' minimamente processada. Brazilian Journal of Food Technology, Campinas, v. 18, n. 2, p. 85-92, 2015. http://dx.doi.org/10.1590/1981-6723.2814.

KLUGE, R. A.; COSTA, C. A.; VITTI, M. C. D.; ONGARELLI, M.; JACOMINO, A. P.; MORETTI, C. L. Armazenamento refrigerado de beterraba minimamente processada em diferentes tipos de corte. Ciência Rural, Santa Maria, v. 36, n. 1, p. 263-270, 2006. http://dx.doi.org/10.1590/S0103-84782006000100041.

KLUGE, R. A.; GEERDINK, G. M.; TEZOTTO-ULIANA, J. V.; GUASSI, S. A. D.; ZORZETO, T. Q.; SASAKI, F. F. C.; COSTA, S. M. Qualidade de pimentões amarelos minimamente processados tratados com antioxidantes. Semina: Ciências Agrárias, Londrina, v. 35, n. 2, p. 801-812, 2014.

LATIMER JUNIOR, G. W. (Ed.). Official methods of analysis of the Association of Official Analytical Chemists. 19th ed. Gaithersburg: AOAC, 2012. 3000 p.

MORETTI, C. L.; MATTOS, L. M. Processamento mínimo. In: LUENGO, R. F. A.; CALBO, A. G. (Ed). Pós-colheita de hortaliças: o produtor pergunta, a Embrapa responde. Brasília: Embrapa Informação Tecnológica, 2011. 251 p. (Coleção 500 perguntas, 500 respostas).

NASCIMENTO, L. M.; ARRUDA, M. C.; FISCHER, I. H.; FERRAZ, L. P.; FONSECA, M. B. Potencial de conservação de tangerina W Murcott: armazenamento refrigerado $\times$ atmosfera modificada. Citrus Research \& Technology, Cordeirópolis, v. 32, n. 3, p. 167-172, 2011. http://dx. doi.org/10.5935/2236-3122.20110020.

ODRIOZOLA-SERRANO, I.; HERNÁNDEZ-JOVER, T.; MARTÍNBELLOSO, O. Comparative evaluation of UV-HPLC methods and reducing agents to determine vitamin $\mathrm{C}$ in fruits. Food Chemistry, London, v. 105, n. 3, p. 1151-1158, 2007. http:// dx.doi.org/10.1016/j.foodchem.2007.02.037.

OMS-OLIU, G.; HERTOG, M. L. A. T. M.; VAN DE POEL, B.; AMPOFO-ASIAMA, J.; GEERAERD, A. H.; NICOLAÏ, B. M. Metabolic characterization of tomato fruit during preharvest development, ripening, and postharvest shelf-life. Postharvest Biology and Technology, Amsterdam, v. 62, n. 1, p. 7-16, 2011. http://dx.doi. org/10.1016/j.postharvbio.2011.04.010.

OMS-OLIU, G.; ROJAS-GRAÜ, M. A.; GONZALEZ, L. A.; VARELA, P.; SOLIVA-FORTUNY, R.; HERNANDO, M. I. H.; MUNUERA, I. P.; FISZMAN, S.; MARTÍN-BELLOSO, O. Recent approaches 
Processamento mínimo de tangor 'Murcott': tipos de corte, sanificação e eliminação do excesso de líquidos Chiarini, R. F. et al.

using chemical treatments to preserve quality of fresh-cut fruit: a review. Postharvest Biology and Technology, Amsterdam, v. 57, n. 3, p. 139-148, 2010. http://dx.doi.org/10.1016/j. postharvbio.2010.04.001.

PHUA, L. K.; NEO, S. Y.; KHOO, G. H.; YUK, H. G. Comparison of the efficacy of various sanitizers and hot water treatment in inactivating inoculated foodborne pathogens and natural microflora on mung bean sprouts. Food Control, Guildford, v. 42, p. 270-276, 2014. http://dx.doi.org/10.1016/j.foodcont.2014.02.013.

PINHEIRO, A. L.; JACOMINO, A. P.; ARRUDA, M. C. D.; RIBEIRO, R. V.; KLUGE, R. A.; TREVISAN, M. J. Peeling of' 'Pera' sweet orange related to the duration of the hydrothermal treatment. Ciência Rural, Santa Maria, v. 39, n. 6, p. 1857-1863, 2009. http://dx.doi.org/10.1590/S0103-84782009000600034.

PIO, R. M.; AZEVEDO, F. A. D.; NEGRI, J. D. D.; FIGUEIREDO, J. O. D.; CASTRO, J. L. D. Características da variedade Fremont quando comparadas com as das tangerinas 'Ponkan' e 'Clementina Nules'. Revista Brasileira de Fruticultura, Jaboticabal, v. 28, n. 2, p. 222-226, 2006. http://dx.doi.org/10.1590/S010029452006000200015.
SAS INSTITUTE. SAS/STAT ${ }^{\circledR}$ 9.3: user's guide. 2nd ed. Cary, 2010. SILVA, A. P. G.; SILVA, S. M.; SCHUNEMANN, A. P. P.; DANTAS, A. L.; DANTAS, R. L.; SILVA, J. A.; MENDONÇA, R. M. N. Índice de identidade e qualidade de tangerina 'Ponkan' produzida no estado da Paraíba. Revista Agropecuária Técnica, Paraíba, v. 35, n. 1, p. 143-149, 2014.

SILVA, N.; JUNQUEIRA, V. C. A.; SILVEIRA, N. F. A.; TANIWAKI, M. H.; SANTOS, R. F. S.; GOMES, R. A. R. Manual de métodos de análise microbiológica de alimentos. 3. ed. São Paulo: Livraria Varela, 2007. 552 p.

SOUZA, B. S.; DURIGAN, J. F.; DONADON, J. R.; TEIXEIRA, G. H. A. Conservação de mamão 'Formosa' minimamente processado armazenado sob refrigeração. Revista Brasileira de Fruticultura, Jaboticabal, v. 27, n. 2, p. 273-276, 2005. http:// dx.doi.org/10.1590/S0100-29452005000200021.

SREBERNICH, S. M. Utilização do dióxido de cloro e do ácido peracético como substitutos do hipoclorito de sódio na sanitização do cheiro-verde minimamente processado. Ciência e Tecnologia de Alimentos, Campinas, v. 27, n. 4, p. 744-750, 2007. http:// dx.doi.org/10.1590/S0101-20612007000400012. 